\title{
PENGETAHUAN IBU HAMIL TENTANG INISIASI MENYUSU DINI
}

\author{
${ }^{1}$ Florence T. U. Latuharhary \\ ${ }^{2}$ Eddy Suparman \\ ${ }^{2}$ Hermie M. M. Tendean
}

\author{
${ }^{1}$ Kandidat Skripsi Fakultas Kedokteran Universitas Sam Ratulangi Manado \\ ${ }^{2}$ Bagian Obstetri \& Ginekologi Fakultas Kedokteran Universitas Sam Ratulangi Manado \\ Email: flo_hary737@yahoo.com
}

\begin{abstract}
Early breastfeeding initiation is babies' immediate self-suckle within an hour after being born. However, according to one of the aforetime researches, only $4 \%$ women in Indonesia did early breastfeeding initiation, while the other $96 \%$ ones did not. Objective: to observe the expectant mothers' cognition about the early breastfeeding initiation in polyclinic gynecologist/Obstetrics BLU RSU Prof. Dr. R. D. Kandou Manado, periode NovemberDecember 2013. Method: this research use descriptive research design with cross-sectional study approach. This research was carried out in November-December, 2013. The sample of the study was 50 expectant mothers checking their pregnancy at polyclinic gynecologist/Obstetrics BLU RSU Prof. Dr. R. D. Kandou Manado. Results: it was found that the associate knowledge upon early breastfeeding initiation according to the age group, exist in the age group $<20$ year (100\%), according to the level of education, exist in university level $(100 \%)$, and according to the number of children, exist in expectant mother with one child (100\%). Conclusion: Overall, expectant mothers' cognition upon early breastfeeding initiation in good category (96\%), while in bad category (4\%).
\end{abstract}

Keywords: expectant mothers' cognition, early breast feeding initiation.

\begin{abstract}
Abstrak: Inisiasi Menyusu Dini (IMD) adalah segeranya bayi menyusu sendiri dalam satu jam pertama setelah lahir. Namun menurut salah satu survei yang telah dilakukan, pelaksanaan inisiasi menyusu dini hanya dilakukan oleh $4 \%$ wanita di Indonesia sedangkan 96\% wanita lainnya tidak mempraktekkannya. Tujuan: Mengetahui pengetahuan ibu hamil tentang inisiasi menyusu dini di Poliklinik Kandungan/Obstetri BLU RSU Prof. Dr. R. D. Kandou Manado periode November-Desember 2013. Metode: Penelitian ini menggunakan desain penelitian deskriptif dengan pendekatan cross-sectional study. Penelitian ini dilakukan pada bulan November-Desember 2013 dengan sampelnya adalah ibu hamil yang memeriksakan kehamilannya ke Poliklinik Kandungan/Obstetri BLU RSU Prof. Dr. R. D. Kandou Manado yang berjumlah 50 orang. Hasil: Didapatkan hasil pengetahuan yang baik tentang inisiasi menyusu dini menurut kelompok umur ada pada kelompok umur $<20$ tahun (100\%), menurut pendidikan terakhir ada pada tingkat perguruan tinggi (100\%) dan menurut jumlah anak ada pada ibu hamil yang memiliki satu anak (100\%). Simpulan: Secara keseluruhan, pengetahuan ibu hamil tentang inisiasi menyusu dini dalam kategori baik (96\%) sedangkan untuk kategori buruk (4\%).
\end{abstract}

Kata kunci: Pengetahuan ibu hamil, inisiasi menyusu dini.

Dalam pembangunan bangsa, peningkatan kualitas manusia harus dimulai sedini mungkin, yaitu sejak masih bayi. Salah satu faktor yang memegang peranan penting dalam peningkatan kualitas manusia adalah pemberian Air Susu Ibu (ASI). ${ }^{1}$ Pemberian ASI yang benar adalah dengan menyusui, dimana menyusui merupakan proses 
fisiologis untuk memberikan nutrisi kepada bayi secara optimal. Tidak ada hal yang lebih bernilai dalam kehidupan seorang anak selain memperoleh nutrisi yang berkualitas sejak awal kehidupannya. ASI merupakan nutrisi ideal untuk menunjang kesehatan, pertumbuhan dan perkembangan bayi secara optimal. $^{2}$

Mengingat pentingnya pemberian ASI bagi tumbuh kembang yang optimal baik fisik maupun mental dan kecerdasannya, maka perlu perhatian agar pemberian ASI dapat terlaksana dengan benar. ${ }^{3}$ Keberhasilan ASI eksklusif sangat ditentukan oleh inisiasi menyusu segera setelah dilahirkan, atau dikenal sebagai Inisiasi Menyusu Dini (IMD). IMD adalah kontak kulit antara ibu dan bayi segera setelah lahir danbayi menyusu sendiri dalam 1 jam pertama setelah dilahirkan. ${ }^{4}$

Sebuah survei di Indonesia menunjukkan bahwa hanya 4\% wanita Indonesia yang melaksanakan IMD sedangkan 96\% lainnya tidak mempraktekkannya. ${ }^{5}$ Padahal, sekitar 21.000 kematian bayi baru lahir (usia di bawah 28 hari) di Indonesia dapat dicegah melalui pemberian ASI pada satu jam pertama setelah lahir. Pemberian ASI dini juga meningkatkan kemungkinan 2-8 kali lebih besar untuk ibu memberi ASI eksklusif. ${ }^{6}$

Menurut Departemen Kesehatan tahun 2007, beberapa penyebab kematian bayi dikarenakan 29\% Berat Badan Lahir Rendah (BBLR), 27\% asfiksia, 10\% tetanus, $5 \%$ infeksi, $6 \%$ masalah hematologi, $10 \%$ masalah pemberian minuman, dan lainnya sebanyak 27\%. Dalam Millenium Development Goals (MDGs), Indonesia menargetkan pada tahun 2015 AKB menurun menjadi 17 bayi per 1.000 kelahiran. Karena itu diadakan program kesehatan anak yang mampu menurunkan angka kesakitan dan kematian pada anak. Beberapa program terkini dalam proses pelaksanaan percepatan penurunan Angka Kematian Bayi (AKB) adalah program Inisiasi Menyusu Dini (IMD), ASI eksklusif, penyedia konsultan ASI eksklusif di rumah sakit atau puskesmas, injeksi vitamin $\mathrm{K}$ pada bayi baru lahir, imunisasi hepatitis pada bayi kurang dari 7 hari, tatalaksana gizi buruk, dan program lainnya. World Health Organization (WHO) dan United Nation Childrens Fund (UNICEF) pada tahun 2007, mengeluarkan protokol baru tentang “ASI segera” sebagai tindakan "life saving" atau untuk menyelamatkan kehidupan bayi baru lahir. ${ }^{1}$

\section{BAHAN DAN METODE}

Penelitian ini menggunakan desain penelitian deskriptif dengan pendekatan cross-sectional study dimana peneliti hanya melakukan observasi atau pengukuran mengenai pengetahuan ibu hamil tentang inisiasi menyusu dini pada satu saat tertentu. Penelitian akan dilakukan di Poliklinik Obstetri BLU RSU Prof. Dr. R. D. Kandou Manado, denganwaktupenelitianpadabulan November-Desember 2013. Sampelnya adalah para ibu hamil yang datang memeriksakan kehamilan yang berjumlah 50 orang.

Data yang digunakan dalam penelitian ini adalah data primer, dimana data yang didapat melalui kuesioner yang diberikan secara langsung kepada responden. Kemudian data yang diperoleh akan dikumpulkan dan diolah menggunakan menggunakan program SPSS versi 20, lalu ditampilkan atau disajikan dalam bentuk Tabel distribusi frekuensi.

\section{HASIL DAN PEMBAHASAN}

\section{Karakteristik Responden}

Tabel dibawah adalah Tabel distribusi karakteristik responden menurut umur, pendidikan terakhir, dan jumlah anak, menunjukkan bahwa responden terbanyak yang berpartisipasi menurut kelompok umur ada pada rentang umur 20-25 tahun (26\%), lalu diikuti oleh kelompok umur 31-35 tahun (22\%), kelompok umur $<20$ tahun (20\%), kelompok umur $>35$ tahun (18\%), dan yang paling sedikit pada kelompok umur 26-30 tahun. Ini sesuai dengan hasil penelitian dari Wahyuningsih (2009) yang berjudul Hubungan Pengetahuan Ibu Bersalin dengan Inisisasi Menyusu Dini di Bidan Praktek Swasta Benis Jayanto 
Ngentak Kunjo Ceper Klaten, dimana kelompok umur terbanyak yang menjadi responden ada pada kelompok umur 20-35 tahun (92\%). ${ }^{9}$

Tabel 1. Distribusi responden berdasarkan karakteristik

\begin{tabular}{ccc}
\hline Karakteristik & $\mathbf{n}$ & $\mathbf{\%}$ \\
\hline Kelompok Umur (tahun) & & \\
$<20$ & 10 & 20 \\
$20-25$ & 13 & 26 \\
$26-30$ & 7 & 14 \\
$31-35$ & 11 & 22 \\
$>35$ & 9 & 18 \\
Total & 50 & 100 \\
SD & & \\
SMP & 1 & 2 \\
SMA & 8 & 16 \\
Pendidikan Terakhir & 28 & 56 \\
Perguruan Tinggi & 13 & 26 \\
Total & 50 & 100 \\
Jumlah Anak & & \\
0 & 25 & 50 \\
1 & 11 & 22 \\
2 & 10 & 20 \\
3 & 4 & 8 \\
\hline
\end{tabular}

Pada Tabel tersebut juga menunjukkan bahwa responden terbanyak menurut pendidikan terakhir ada pada tingkat SMA (56\%), lalu diikuti tingkat perguruan tinggi (26\%), tingkat SMP (16\%), dan yang paling sedikit berpartisipasi adalah pada tingkat SD (2\%). Ini sesuai dengan hasil penelitian dari Haniarti (2011) yang berjudul Pengaruh Edukasi Terhadap Perubahan Pengetahuan dan Sikap Inisiasi Menyusu Dini pada Ibu
Hamil di Kota Pare-pare, dimana pendidikan terakhir terbanyak yang menjadi responden atau yang ikut berpartisipasi ada pada tingkat SMA $(49,6 \%){ }^{5}$

Untuk jumlah anak pada Tabel tersebut pun menunjukkan bahwa reponden terbanyak yang mengikuti penelitian ini ada pada ibu yang belum memiliki anak (50\%), lalu diikuti oleh ibu yang memiliki satu anak (22\%), ibu yang memiliki 2 anak (20\%), dan yang paling sedikit ada pada ibu yang memiliki tiga anak (8\%). Ini tidak sesuai dengan hasil penelitian dari Issyaputri (2011) yang berjudul Faktor yang Berhubungan dengan Ibu Melakukan Inisisasi Menyusu Dini di RSIA Siti Fatimah Makassar, dimana responden terbanyak yang mengikuti penelitian tersebut adalah ibu yang memiliki anak lebih dari dua $(57,4 \%)^{6}$

\section{Karakteristik kategori variabel}

Tabel dibawah adalah Tabel distribusi pengetahuan ibu hamil tentang inisiasi menyusu dini menurut kelompok umur, didapatkan hasil dengan kategori pengetahuan yang baik ada pada kelompok umur $<20$ tahun. Dimana hasil pengetahuan yang baik didapatkan sebesar $100 \%$ dari 10 responden. Dengan bertambahnya umur seseorang, akan terjadi perubahan pada aspek psikis dan psikologis (mental) dimana taraf berpikir seseorang semakin matang dan dewasa. Namun dalam penerimaan informasi, semakin muda umur informasi yang ada akan lebih mudah diserap dan diterima dibanding dengan umur yang lebih tua.

Tabel 2. Pengetahuan ibu hamil tentang inisiasi menyusu dini menurut kelompok umur

\begin{tabular}{cccccc}
\hline \multirow{2}{*}{$\begin{array}{c}\text { Kelompok } \\
\text { Umur }\end{array}$} & $\sum(\mathbf{n})$ & \multicolumn{3}{c}{ Pengetahuan } \\
\cline { 3 - 6 } (Tahun) & & Baik & n & n & Buruk \\
\cline { 3 - 6 } & 10 & 10 & 100 & 0 & 0 \\
\hline 20 & 13 & 12 & 92.3 & 1 & 7.7 \\
$20-25$ & 7 & 7 & 100 & 0 & 0 \\
$26-30$ & 11 & 10 & 90.9 & 1 & 9.1 \\
$31-35$ & 9 & 9 & 100 & 0 & 0 \\
$>35$ & 50 & 48 & 96 & 2 & 4 \\
Total & & & & &
\end{tabular}


Jurnal e-CliniC (eCl), Volume 2, Nomor 2, Juli 2014

Tabel 3. Distribusi pengetahuan ibu hamil tentang inisiasi menyusu dini menurut pendidikan terakhir

\begin{tabular}{cccccc}
\hline \multirow{2}{*}{$\begin{array}{c}\text { Pendidikan } \\
\text { Terakhir }\end{array}$} & $\sum(\mathbf{n})$ & \multicolumn{3}{c}{ Pengetahuan } \\
\cline { 3 - 6 } & & $\mathbf{n}$ & $\mathbf{\%}$ & $\mathbf{n}$ & $\mathbf{\%}$ \\
\cline { 3 - 6 } & 1 & 1 & 100 & 0 & 0 \\
SD & 8 & 7 & 87.5 & 1 & 12.5 \\
SMP & 28 & 27 & 96.4 & 1 & 3.6 \\
SMA & 13 & 13 & 100 & 0 & 0 \\
Perguruan Tinggi & 13 & 96 & 2 & 4 \\
Total & 50 & 48 & &
\end{tabular}

Karena umur yang lebih tua telah mempunyai banyak pengalaman sehingga itu menjadi salah satu pertimbangan dalam menyerap informasi yang ada.,8,10

Tabel 3 adalah Tabel distribusi pengetahuan ibu hamil tentang inisiasi menyusu dini menurut pendidikan terakhir responden, didapatkan hasil untuk kategori pengetahuan yang baik tertinggi pada tingkat Perguruan Tinggi sebesar 100\% dari 13 responden. Pada tingkat SD persentase pengetahuan tentang inisiasi menyusu dini pun menunjukkan 100\%, namun karena jumlah respondennya hanya satu orang maka pengetahuan yang baik tertinggi ada pada tingkat Perguruan Tinggi. Pendidikan adalah bimbingan yang diberikan seseorang kepada orang lain terhadap suatu hal agar mereka dapat memahami. Semakin tinggi tingkat pendidikan seseorang, semakin mudah seseorang tersebut menerima informasi, begitu pula sebaliknya. Dengan pendidikan tinggi maka seseorang akan cenderung mendapatkan informasi, baik dari orang lain maupun media massa. Semakin banyak informasi yang masuk semakin banyak pula informasi yang didapatkan tentang kesehatan. Pengetahuan sangat erat kaitannya dengan pendidikan dimana diharapkan seseorang dengan pendidikan tinggi, maka semakin luas pula pengetahuannya. ${ }^{7,8,10}$

Tabel 4 adalah Tabel distribusi pengetahuan ibu hamil tentang inisiasi menyusu dini menurut jumlah anak, didapatkan hasil sebesar $100 \%$ (11 responden) untuk ibu hamil yang mempunyai satu anak. Hal ini menunjukkan bahwa pada penelitian ini, ibu hamil yang menjadi responden telah memiliki pengetahuan yang lebih baik dari yang sudah memiliki $\geq 2$ anak. Karena sebelum mereka memiliki anak, mereka telah mempersiapkan setiap hal yang dibutuhkan untuk memberikan yang terbaik bagi anak mereka. Untuk mempersiapkan hal tersebut, mereka mencari informasi terlebih dahulu tentang kehamilan sampai perawatan anak, salah satunya dengan mencari informasi tentang inisiasi menyusu dini. Informasi yang didapatkan, diperoleh melalui kenyataan (melihat dan mendengar sendiri), serta melalui surat kabar, radio, tv dapat menambah pengetahuan agar lebih luas. Selain itu, pengalaman dari kehamilan anak yang pertama merupakan tolak ukur bagi si ibu untuk lebih baik lagi dalam mempersiapkan kehamilannya saat ini. ${ }^{7,8,10}$

Tabel 4. Distribusi pengetahuan ibu hamil tentang inisiasi menyusu dini menurut jumlah anak

\begin{tabular}{cccccc}
\hline \multirow{2}{*}{ Jumlah Anak } & \multirow{2}{*}{$(\mathbf{n})$} & \multicolumn{3}{c}{ Pengetahuan } & \multicolumn{3}{c}{ Buruk } \\
\cline { 3 - 6 } & & $\mathbf{n}$ & $\mathbf{\%}$ & $\mathbf{n}$ & $\mathbf{\%}$ \\
\cline { 3 - 6 } & 25 & 24 & 96 & 1 & 4 \\
1 & 11 & 11 & 100 & 0 & 0 \\
2 & 10 & 10 & 100 & 0 & 0 \\
3 & 4 & 3 & 75 & 1 & 25 \\
Total & 50 & 48 & 96 & 2 & 4 \\
\hline
\end{tabular}




\section{SIMPULAN DAN SARAN}

Berdasarkan penelitian yang telah dilakukan, dapat disimpulkan bahwa secara keseluruhan pengetahuan yang baik tentang inisiasi menyusu dini sebesar $96 \%$ (48 responden) dan kategori pengetahuan yang buruk sebesar 4\% (2 responden). Diharapkan setiap tenaga kesehatan atau pihak-pihak terkait untuk meningkatkan pemberian informasi tentang pentingnya inisiasi menyusu dini, sehingga pengetahuan tentang inisiasi menyusu dini dan pelaksanaannya pun terus meningkat menjadi lebih baik.

\section{DAFTAR PUSTAKA}

1. Khiyarotun N, Noveri A. Hubungan Tingkat Pengetahuan dan Sikap Bidan tentang Inisiasi Menyusu Dini (IMD) dengan Praktik Inisiasi Menyusu Dini di Puskesmas Kota Semarang. Majalah Ilmiah Sultan Agung. 2011; 49(125):2538.

2. Hegar B. NilaiMenyusui. Editor: Suradi R, Partiwi IGAN, Marzuki ANS, Ananta Y. Indonesia Menyusui. BadanPenerbit IDAI; 2010. hal. 1.

3. Wulandari

AS. InisiasiMenyusuDiniuntukAwali ASI Eksklusif [Tesis]. [Surabaya]: Fakultas Kedokteran Wijaya Kusuma; 2013.

4. IrawatiA.INISIASI MENYUSU DINI DAN FAKTOR DETERMINANNYA PADA ANAK BALITA DI INDONESIA: Analisis Data Sekunder Survei Demografi dan Kesehatan Indonesia Tahun 2007. Jurnal Penelitian Gizi dan Makanan. 2010; 33(1):1-13.

5. Haniarti. Pengaruh Edukasi Terhadap Perubahan Pengetahuan Dan Sikap Inisiasi Menyusu Dini (IMD) Pada Ibu Hamil Di Kota Parepare. Kesehatan Masyarakat Indonesia. 2012; 8(4):192-7.

6. Issyaputri AF. Faktor yang Berhubungan dengan Ibu Melakukan Inisiasi Menyusu Dini (IMD) di RSIA Siti Fatimah Makassar Tahun 2011. Kesehatan Masyarakat Indonesia. 2012; 8(4):206.

7. Barus EBR. Pengetahuan dan Sikap Remaja Jalanan tentang Kesehatan Reproduksi di Kota Medan Tahun 2011 [Skripsi]. Medan: Fakultas Keperawatan Universitas Sumatera Utara; 2011.

8. Simanullang SMD. Hubungan Antara Tingkat Pengetahuan Suami tentang Perawatan Kehamilan dengan Partisipasi Suami dalam Perawatan Kehamilan di Klinik Bersalin Mariani Medan [Skripsi]. Medan: Fakultas Keperawatan Universitas Sumatera Utara; 2010.

9. Wahyuningsih. Hubungan Pengetahuan Ibu Bersalin dengan Inisiasi Menyusu Dini di Bidan Praktek Swasta Benis Jayanto Ngentak Kujon Ceper Klaten. Jurnal Komunikasi Kesehatan. 2012; 3(01).

10. Sitompul MT. Pengetahuan Ibu Hamil Tentang Gizi Semasa Kehamilan di Wilayah Kerja Puskesmas Tukka Kabupaten Tapanuli Tengah Tahun 2011 [Skripsi]. Medan: Fakultas Keperawatan Universitas Sumatera Utara; 2012. 